\title{
Médicos e arquitectos: influência e persuasão nas escolhas em saúde
}

António Faria Vaz*

"Diferentemente dos Econs, os humanos previsivelmente erram" ${ }^{1}$

Nudge, como designaremos o conceito, é qualquer aspeto da arquitetura de escolha que altera o comportamento das pessoas de maneira previsível, sem proibir nenhuma opção ou alterar significativamente os seus incentivos económicos. Para contar como um simples nudge, a intervenção deve ser fácil e económica. Nudges não são mandatos. Colocar frutas ao nível dos olhos conta como um nudge. Proibir comida não saudável (junk food), não. ${ }^{2}$

(tradução livre do autor)

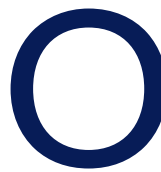

conceito de nudge (influência, persuasão, empurrão) em saúde foi pela primeira vez empregue em 2008, por Richard Thaler, economista comportamental, e por Cass Sustein, jurista, num best-seller publicado. Baseando-se nos resultados da investigação comportamental, refutaram a assunção da economia clássica que afirmava que os consumidores tomam decisões económicas de risco numa perspetiva de maximização da utilidade. Ou seja, quando tomamos decisões de risco procuramos maximizar a sua utilidade (um valor quantificável, mas subjetivo), tendo em conta as consequências e as probabilidades que lhes estão associadas. Por sua vez, os economistas comportamentais usam modelos de escolha pelo consumidor que associam a investigação em psicologia e a investigação comportamental, pretendendo demonstrar que os seres humanos nem

*Médico de família. Comissão de Ética para a Saúde, Administração Regional de Saúde de Lisboa e Vale do Tejo sempre escolhem em conformidade com os modelos propostos pelas teorias clássicas de decisão. ${ }^{3}$

Thaler e Sustein estabelecem a diferença entre o que designam como os «Humanos» e os «Econs». O conceito de Homo economicus, ou homem económico («Econ»), baseia-se na ideia de que as pessoas pensam e escolhem invariavelmente bem, conquanto o mesmo não possa ser dito a respeito do Homo sapiens («Humanos»). Nós, os sapiens, esquecemo-nos de coisas e, por vezes, fazemos más escolhas. Para os autores, os humanos são reais e os Econs são imaginários. É fundamental identificar essas diferenças enquanto arquitetos de escolhas, pois devem ser tidas em consideração quando se desenvolve uma nudge.

Richard Thaler recebeu o Prémio Nobel da Economia em 2017 pela sua significativa contribuição para o estudo da economia comportamental nas últimas quatro décadas. Thaler questionou e investigou a assunção da «racionalidade» (da economia clássica) e demonstrou com sucesso que a psicologia humana e o contexto desempenham um papel essencial nas decisões humanas, concluindo que, "diferentemente dos Econs, os humanos previsivelmente erram". Thaler e os economistas comportamentais forneceram novas ferramentas para a compreensão do comportamento humano e, mais importante, ferramentas para o prever e para o influenciar. ${ }^{4}$

Daniel Kaheman, teórico da economia comportamental, Prémio Nobel da Economia em 2002, procurou explicar o comportamento aparentemente irracional da gestão do risco pelos seres humanos. Descreveu, com Amos Tversky, teórico da ciência cognitiva, os processos cognitivos humanos de processamento da informação que explicam por que razão as pessoas agem contra o seu próprio interesse: o sistema 1 é rápido, automático e altamente sensível ao contexto; o sistema 2 processa a informação de uma forma lenta, reflexiva e 
pondera os objetivos e as intenções no processo de decisão.

Nas escolhas ou nas decisões, o Sistema Automático poderia ser considerado uma reação «medular» (pavloviana) e o Sistema Reflexivo seria o nosso pensamento consciente. Um dos objetivos do nudge é o de incentivar as pessoas a decisões em que possam confiar no Sistema Automático para que logrem levar uma vida mais fácil, melhor e mais longa. O nudging (o processo de influenciar, de empurrar) procura retirar vantagens do sistema 1, promovendo escolhas benéficas e em saúde que promovam o bem-estar das pessoas.

$\mathrm{O}$ nudge diz, portanto, respeito às técnicas de influenciar as escolhas dos cidadãos, quer em políticas de saúde (governamentais) quer na relação médico-doente (ao nível clínico). ${ }^{5}$

O conceito de $n u d g e$ e a sua interpretação, em particular a ideia de que se pode influenciar as escolhas dos cidadãos induzindo alterações de comportamento, escolhas saudáveis, escolhas racionais, na saúde, na economia e na sociedade, determinaram um extenso investimento dos governos na elaboração de estratégias que concretizassem esses potenciais benefícios para os cidadãos e para a sociedade.

No Reino Unido foi criada uma unidade nacional de nudge (British Behavioural Insights Team), ${ }^{6}$ nos Estados Unidos da América o Presidente Obama designou Sustein para dirigir uma unidade especializada, na Austrália o governo da Nova Gales do Sul estabeleceu uma unidade designada por Behavioural Insights Community e, surpreendentemente, o governo de Boris Johnson decidiu que o combate ao coronavírus deveria ser suportado pela «teoria do $n u d g e » .{ }^{7}$ Note-se que a unidade britânica, agora designada por Bi. Team, é uma companhia global com escritórios em mais de 31 países e tem como missão sustentar a decisão política, melhorar os serviços públicos e o retorno público dos resultados.

A Organização para a Cooperação e Desenvolvimento Económico (OCDE) publicou um relatório, em 2017, onde relata a utilização das nudges e descreve mais de 100 iniciativas em diversos países, afirmando a sua aplicação em políticas públicas, que vão da redução da obesidade, às estratégias de doação de órgãos, passando pela promoção de genéricos até à desburocratização dos serviços públicos. ${ }^{8}$
Deveria então considerar-se, na prática clínica, que as escolhas dos doentes são sempre aceitáveis e que tal pressuposto se justifica quando se assume que a autonomia é um valor superior e absoluto que deveremos sempre respeitar? Mesmo quando essas escolhas não sejam clínica e epidemiologicamente aceitáveis, nomeadamente nas situações em que existem alternativas mais beneficentes e efetivas?

E a sociedade (nas políticas de saúde) ou o médico (na sua relação fiduciária com os doentes) deveriam procurar influenciar/persuadir/empurrar - nudge-os cidadãos (doentes ou não) em escolhas que lhes sejam benéficas, mesmo que essa intervenção possa, no limite, violar a sua autonomia e a sua confiança? Pode ainda considerar-se que esse empurrão tem um valor moral superior ao do respeito pela dignidade humana, porque os benefícios para a sociedade (e para o indivíduo) o justificam?

Os resultados dos estudos que têm vindo a ser publicados, relativos ao nudge em política de saúde, demonstram-nos que as pessoas valorizam mais os aspetos morais do que a efetividade das medidas que lhes são propostas, em particular se quando fala de aspetos relacionados com a mudança de estilos de vida.

No entanto, os poucos estudos que abordaram o papel do nudge na relação clínica parecem demonstrar diferenças significativas entre os médicos e os doentes nas respetivas apreciações. De facto, os doentes consideram que o nudge é um fator que pode potencialmente pôr em risco a autonomia (e o consentimento) e a relação médico-doente. Os médicos, por sua vez, não valorizam de idêntica forma o nudge na relação clínica. Assim, pode considerar-se que as pessoas não-profissionais de saúde valorizam mais os aspetos éticos associados ao nudge que a sua eficácia. ${ }^{9}$

Deste modo, a influência / a persuasão / o empurrão (nudge) é matéria de profundo debate ético entre os que defendem a sua necessidade e os que consideram que a sua utilização fere princípios éticos fundamentais. Encontrar o equilíbrio entre a persuasão (nudge) e o respeito pela autonomia é uma das controvérsias éticas mais recentes, que interessará valorizar.

Nesta disputa, e atendendo aos fundamentos teóricos e conceptuais do nudge e, em particular, aos mecanismos de decisão associados ao processo cognitivo de escolha, diríamos, de imediato, que um 
procedimento que apela ao automatismo de decisão é, por definição, contrário ao respeito pela dignidade humana e à autonomia que obriga a que os atos médicos sejam consentidos pelos doentes, ressalvando, para os mais críticos e mais próximos do paternalismo, que o consentimento livre e esclarecido é na sua maioria verbal e não escrito, decorrente da relação de mútua confiança médico-doente. Esta vincula-se mais ao direito que à relação humana própria do exercício clínico. Simulekt afirma que o nudgingé incompatível com a verdade na obtenção do consentimento. Por sua vez, Kelling declara que os nudges, por não fazerem apelo à razão, não respeitam a autonomia individual. ${ }^{10-11}$ Whertheimer defende que a oportunidade para viver uma vida ou uma vida autónoma, no futuro, poderia ser comprometida se as pessoas fizessem escolhas erradas. $^{12}$

Burgess, focando-se nas experiências inglesas em que a estratégia comportamental foi considerada como alternativa à regulação e ao mercado, revela-nos que a atratividade e a sedução do nudging assentam na sua maior aceitabilidade em contexto de crise económica, em que os aspetos relacionados com o direito à privacidade e à reserva da intimidade são menos problemáticos. A própria crise motivaria a perda de direitos. ${ }^{13}$

Outros defendem, como Cohen, que o conceito de nudging pode ser aplicado à prática clínica para ajudar a resolver o conflito entre dois princípios éticos fundamentais: o respeito pela autonomia e a promoção do bem-estar. O conflito surgiria no momento em que um doente tomasse uma decisão contrária aos seus interesses e à sua saúde. Neste caso justificar-se-ia, para o autor, que o médico influenciasse os seus doentes, uma vez que os médicos são os arquitetos das escolhas em saúde, a optar por uma escolha que fosse melhor para a sua saúde sem invalidar o consentimento e promovendo o bem-estar e a saúde dos doentes. ${ }^{14}$

Os médicos seriam, assim, arquitetos das escolhas e eram-no mesmo antes de existir o conceito de nudge: quando proporcionam aos seus doentes informação, recomendações e lhes apresentam as diversas alternativas possíveis, ou melhor, as escolhas possíveis. A forma como se expressa a informação, o modo como se recomenda e a maneira como são apresentadas as alternativas influencia as escolhas dos doentes. Neste contexto, diríamos que o nudge não acrescenta nada de novo à relação clínica, a medicina e o seu exercício implicam de alguma forma a capacidade de influenciar as escolhas dos cidadãos, não deixando de cumprir os princípios do respeito pela dignidade humana, da beneficência e da não maleficência.

Saghai defende a eticidade do nudge em contexto de saúde pública. Para tal, refuta os modelos de tomada de decisão de Daniel Kaheman e propõe, em alternativa, a teoria dos três procedimentos de decisão de Keith Stanovich; com base neste pressuposto conceptual que preserva a liberdade de escolha e o processo cognitivo deliberativo, o nudge seria eticamente sustentável. ${ }^{15-16}$

A arquitetura de escolha poderia constituir-se como um bom elemento conceptual de suporte à prática clínica e em saúde pública, promovendo a adoção de estilos saudáveis e melhorando a qualidade de vida de doentes e cidadãos, desde que sejam garantidos os preceitos éticos e os direitos cívicos fundamentais.

A dúvida poderá não se situar na beneficência proposta pelo nudge; se considerássemos apenas esta perspetiva seria consensual a sua adoção, quer na relação clínica quer em termos de saúde pública. Uma das questões cruciais é a de saber se as preferências e, diria, os valores dos promotores do nudge são as dos nudgees (sujeitos da intervenção) e de que forma e com que direito alguém assume que o paternalismo é afinal a melhor forma de assegurar uma relação clínica, seja ela individual ou coletiva. Existe, de facto, uma enorme contradição entre os pressupostos enunciados por Thaler e Sustein no seu paternalismo libertário e a sua concretização prática, na medida em que, em absoluto, qualquer influência não legítima, porque não foi outorgada pelo doente, pode respeitar a autonomia e a liberdade do doente.

Desde há muito que vimos defendendo a necessidade, no Serviço Nacional de Saúde, de unidades, independentes, de informação e inteligência, que nos permitam interpelar as nossas práticas e promovam a aquisição inteligente de conhecimento. ${ }^{17}$ Inteligência, que nos permita promover a saúde, tratar os doentes, reduzindo desperdícios, agilizando procedimentos e otimizando recursos. E a sustentabilidade de um Serviço Nacional de Saúde aprendente e inteligente ao serviço dos cidadãos.

A tão falada sustentabilidade do Serviço Nacional de Saúde não pode dispensar esta capacidade de 
aquisição de conhecimento crítico, que vai do delineamento das práticas à respetiva avaliação, incluindo o conhecimento epidemiológico, a epidemiologia do medicamento, as tecnologias de saúde, a qualificação terapêutica (normas e decisão de financiamento), sendo que o acolhimento do nudge como um dos componentes dessa estratégia apenas deveria ter lugar se cumpridos os preceitos éticos inerentes à prestação de cuidados de saúde individual ou coletiva.

E não poderia terminar sem acrescentar que o corpo constituinte de uma unidade de inteligência do Serviço Nacional de Saúde deve dispor da capacidade de avaliação técnica, clínica e epidemiológica, mas, obrigatória e imperativamente, deve associar a apreciação ética na ótica dos doentes, dos profissionais de saúde e do Serviço Nacional de Saúde.

E a epidemia da infeção por COVID-19 demonstrou-nos, com exaustão, a necessidade de o Serviço Nacional de Saúde dispor dessa unidade, aliando a técnica à ética na promoção de valores e de uma cultura de cidadania e de inteligência.

\section{REFERÊNCIAS BIBLIOGRÁFICAS}

1. Schweizer M. Nudging and the principle of proportionality. In: Mathis K, Tor A, editors. Nudging: possibilities, limitations and applications in European law and economics. Cham: Springer; 2016. p. 93-120. ISBN 9783319806006

2. Thaler RH, Sunstein CR. Nudge: improving decisions about health, wealth, and happiness. New York: Penguin Books; 2009. ISBN 9780143115267

3. Amir $\mathrm{O}$, Lobel $\mathrm{O}$. Liberalism and lifestyle: informing regulatory governance with behavioural research. Eur J Risk Regul. 2012;3(1):17-25.
4. Kaushiva A. Nobel Laureate Richard Thaler's contribution to behavioral economics: a brief review. Int J Res Econ Soc Sci. 2017;7(12): 972-81.

5. Saghai Y. Salvaging the concept of nudge. J Med Ethics. 2013;39(8): 487-93.

6. COVID-19: a behavioural perspective [homepage]. Behavioural Insights Team; 2020 [cited 2020 May 15].Available from: https://www.bi.team/

7. Coronavirus (COVID-19) [homepage]. Gov.uk; 2020 [cited 2020 May 17]. Available from: https://www.gov.uk/coronavirus

8. Organisation for Economic Cooperation and Development. Behavioural insights and public policy: lessons from around the world. Paris: OECD; 2017. ISBN 9789264270480

9. Avitzour D, Barnea R, Avitzour E, Cohen H, Nissan-Rozen I. Nudging in the clinic: the ethical implications of differences in doctors' and patients' point of view. J Med Ethics. 2019;45(3):183-9.

10. Simkulet W. At odds with the truth. J Med Ethics. 2018;44(8):548-50.

11. Kelling G. Autonomy, nudging and post-truth politics. J Med Ethics. 2018;44(10):721-2.

12. Wertheimer A. Should 'nudge' be salvaged? J Med Ethics. 2013; 39(8):498-9.

13. Burgess A. 'Nudging' healthy lifestyles: the UK experiments with the behavioural alternative to regulation and the market. Eur J Risk Regul. 2012;3(1):3-16.

14. Cohen S. Nudging and informed consent. Am J Bioeth. 2013;13(6):311.

15. Stanovich KE, West RF, Toplak ME. The rationality quotient: toward a test of rational thinking. Cambridge, MA: The MIT Press; 2016. ISBN 9780262034845

16. Yashar S. The ethics of public health nudges [dissertation]. Washington, DC: Georgetown University; 2012.

17. Vaz AF, editor. Política do medicamento, dispositivos médicos e avaliação de tecnologias em saúde: plano nacional de saúde 2011-2016. [Lisboa]: Alto Comissariado da Saúde; 2010.

\section{ENDEREÇO PARA CORRESPONDÊNCIA}

E-mail: faria.vaz@arslvt.min-saude.pt 